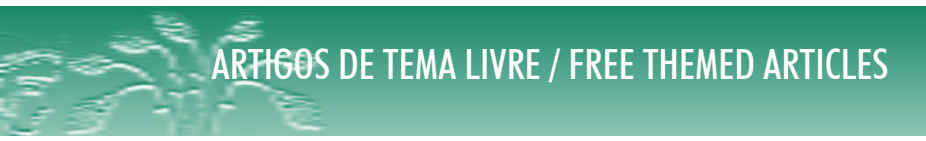

DOI: 10.12957/demetra.2018.28602

\title{
Formação, satisfação e perspectivas profissionais de egressos nutricionistas de uma universidade federal do nordeste brasileiro
}

\author{
Education, satisfaction and professional prospects of nutrition graduates of a federal \\ university in the Brazilian northeast
}

Joana Carla Nunes de Souza'

Andhressa Fagundes ${ }^{2}$

Danielle Góes da Silva²

Kiriaque Barra Ferreira Barbosa ${ }^{3}$

\section{Universidade Federal de Sergipe, Curso de Nutrição. São Cristovão, SE, Brasil. \\ ${ }^{2}$ Universidade Federal de Sergipe, Departamento de Nutrição, Programa de Pós-graduação em Ciências da Nutrição. São Cristovão, SE, Brasil. \\ ${ }^{3}$ Universidade Federal de Sergipe, Departamento de Nutrição, Programas de Pós-graduação em Ciências da Saúde e em Ciências da Nutrição. São Cristovão, SE, Brasil.}

\section{Correspondência / Correspondence} Kiriaque Barra Ferreira Barbosa Departamento de Nutrição, Cidade Univ. Prof. José Aloísio de Campos Av. Marechal Rondon, $s / n$, Jd. Rosa Elze. São Cristóvão-SE, Brasil. CEP: 49.100-000.

E-mail: kiribarra@yahoo.com.br

\section{Resumo}

Objetivos: Identificar o grau de satisfação profissional e de formação dos egressos de curso de graduação em Nutrição. Metodologia: Pesquisa transversal, descritiva, de abordagem quantitativa, com coleta de dados baseada em aplicação de questionário on-line. Os dados categóricos foram apresentados em frequência absoluta e relativa; e os contínuos, em média e desvio padrão. Resultados e discussão: Participaram da pesquisa 57,3\% $(\mathrm{n}=129)$ do total de egressos desde a abertura do curso (2007). A área da Nutrição de maior preferência citada pelos egressos foi a Clínica (41,9\%), e 29,2\% trabalham na área de preferência, sendo que 41,5\% em Nutrição Clínica. Apenas 3,1\% abandonaram a profissão; 29,1\% relataram ter vínculo empregatício com o setor privado; 71,7\% atuam no mesmo estado de formação e $60,2 \%$ demostraram estar insatisfeitos com a remuneração. $\mathrm{O}$ curso foi avaliado de forma bastante positiva, assim como a qualificação dos docentes; com relação às perspectivas profissionais, expressaram interesse em ingressar na docência e aprimorar seus conhecimentos com especialização. Conclusões: A partir deste estudo, foi possível conhecer as dificuldades dos egressos quanto ao curso e à profissão, como a necessidade de mais aulas práticas e a baixa remuneração e carga horária excessiva de trabalho, o que poderá nortear ações futuras e garantir a qualidade do curso.

Palavras-chave: Formação Profissional. Condições de Trabalho. Educação Superior. Nutrição. Área de Atuação Profissional. 


\section{Abstract}

Objectives: To identify the degree of satisfaction of Nutrition graduates with their program and their profession. Methodology: Cross-sectional, descriptive research with a quantitative approach, whose data collection was based on the application of an online questionnaire. Categorical data were presented as absolute and relative frequencies; and the continuums, as average and standard deviation. Results and discussion: $57.3 \%$ (n $=129$ ) of the total of graduates participated in the study since the opening of the course (2007). The field of Nutrition most cited by the graduates was Clinical Nutrition (41.9\%), and $29.2 \%$ worked in their preferredfield, with $41.5 \%$ of them in Clinical Nutrition. Only $3.1 \%$ dropped out; $29.1 \%$ reported having an employment relationship with the private sector; $71.7 \%$ work in the same Brazilian state where they received their degree and $60.2 \%$ are dissatisfied with their wages. The course was evaluated positively, as was teachers'qualification. As regards professional prospects, the interviewees expressed an interest in becoming teachersthemselvesand improving their knowledge with postgraduate studies. Conclusions: This studyoffered insightsinto the difficulties faced bythe graduates regarding the academic programand the profession, such as the need for more practical classes and low pay and excessive work hours. Such awareness could guide future actions and ensurethe quality of the undergraduate program.

Keywords: Professional Qualification. Work Conditions. College Education. Nutrition. Professional Practice Area.

\section{Introdução}

Em 1926, Pedro Escudeiro criou a primeira escola de Nutrição, o Instituto Nacional de Nutrição na América Latina. No Brasil, apenas em 1939 foi criado o primeiro curso de Nutrição, na Faculdade de Saúde Pública da Universidade de São Paulo. No entanto, apenas em 1967 foi regulamentada a profissão de nutricionista, pela Lei no 5.276 , de 24 de abril. ${ }^{1,2}$

Desde então, esse profissional vem ganhando espaço e expandindo seu campo de atuação. O mercado de trabalho vem exigindo mais dos profissionais em vários aspectos: criatividade, iniciativa e produtividade. Por outro lado, vem crescendo no país, nas últimas décadas, o número de cursos de graduação em Nutrição, com milhares de profissionais formados anualmente. ${ }^{3-5}$ 
A formação deve proporcionar, segundo Calças et al. ${ }^{6}$, que os graduados atuem de forma consciente do seu papel social, tornando um agente de transformação na sociedade, coadunando com Pinheiro et al. ${ }^{7}$, que afirmam que a função principal do nutricionista é ser um educador em saúde.

A análise de Toledo ${ }^{8}$ mostra que a missão do nutricionista tem mudado com os anos, pois o estilo de vida da população também vem modificando, consequentemente, o perfil das doenças mais prevalentes. Assim, o papel do nutricionista se adapta à necessidade da população, sempre a favor da saúde pública. Outros estudos trazem o nutricionista como importante promotor de práticas e hábitos alimentares saudáveis, como também protetor e promotor da garantia do direito de todos a uma alimentação adequada e segura. ${ }^{9,10}$

Para um profissional atuar de forma eficiente, são necessários alguns requisitos, que incluem, principalmente, uma boa formação. No país já existem 431 cursos de graduação em Nutrição, entre instituições públicas (73), privadas (346) e especiais (12), e atualmente já são 111.113 nutricionistas registrados nos dez conselhos regionais do país. Com essa expansão, há maior demanda pelo controle da qualidade de ensino. ${ }^{11,12}$

Desde o reconhecimento do curso de Nutrição até os anos recentes, alguns estudos revelaram uma dicotomia entre a teoria e a prática na formação desse profissional, de modo que a busca pelo ensino de forma integrada e articulada durante toda formação é, ainda hoje, um desafio para vários cursos. ${ }^{13}$

Segundo o Conselho Federal de Nutricionistas (CFN), constam 847 nutricionistas cadastrados no estado de Sergipe, inscritos no Conselho Regional de Nutricionistas da 5a até março de 2016. ${ }^{12,14}$ Todavia não há registros de pesquisas sobre a situação desses profissionais nesse estado, assim como em todo país ainda há uma grande lacuna de informações sobre sua formação. Os estudos existentes se concentram nas regiões Sul e Sudeste, com apenas um da região Nordeste e outro no Centro-Oeste.

Traçar o perfil sobre a formação e satisfação desse profissional é de grande relevância para delinear os principais indicadores nacionais, já que essa categoria está em permanente processo de transformação e conquista de novos e diferentes mercados de trabalho., ${ }^{3,15,16}$ Visa atuar em favor da saúde da população, que tem cada vez mais prevalentes as doenças crônicas não transmissíveis, cujos fatores de risco modificáveis têm importante papel atribuído à alimentação.

Assim, em razão da falta de registros de dados relacionados ao tema, este estudo teve como objetivo identificar o grau de satisfação profissional e de sua formação no curso de graduação em Nutrição de uma instituição federal do Nordeste brasileiro. 


\section{Metodologia}

Trata-se de pesquisa transversal, descritiva, estruturada a partir de metodologia com abordagem quantitativa, com coleta de dados baseada em aplicação de questionário on-line.

A população do estudo foi constituída por egressos do curso de graduação em Nutrição da Universidade Federal de Sergipe (UFS), Campus de São Cristóvão, sendo este o único critério de inclusão na amostra. Todos os alunos formados na referida instituição foram convidados a participar, perfazendo um total de 225 nutricionistas, segundo os registros oficiais fornecidos pela instituição. ${ }^{17}$

O questionário foi disponibilizado on-line pelo programa Survey Monkey, sendo enviado, primeiramente, para pré-teste com voluntários graduados em Nutrição por outra instituição do estado de Sergipe, visando verificar a linguagem, clareza e a duração do preenchimento e da participação. A coleta de dados foi realizada no período de novembro de 2016 a janeiro de 2017.

A partir dos dados cadastrais da instituição de ensino superior (IES) estudada, foram coletados: nome completo, matrícula e ano de entrada e conclusão de todos os graduados. O convite com o link do questionário foi enviado para os respectivos e-mails, e foram realizadas divulgações da pesquisa nas redes sociais, buscando maior adesão. Antes de preencher o questionário, o participante tinha acesso ao Termo de Consentimento Livre e Esclarecido, sendo necessário aceitá-lo para efetivar sua participação.

O questionário on-line, elaborado a partir de adaptações de estudos prévios, ${ }^{9,16,18}$ foi estruturado em 30 questões, sendo três perguntas abertas e 27 fechadas. Destas três foram de escala Likert de satisfação (1 muito insatisfeito, 2 insatisfeito, 3 indiferente, 4 satisfeito, 5 muito satisfeito), com a opção da resposta "não se aplica", quando necessário. ${ }^{19}$

O instrumento de coleta de dados foi organizado em três grandes blocos: (1) Identificação do egresso (nome, idade e sexo); (2) Formação (ano de entrada e saída no curso, área de atuação de preferência, participação em atividades extracurriculares durante o curso, formação acadêmica posterior e questões sobre o curso de Nutrição com escala de satisfação geral e de algumas variáveis como adequação do currículo/disciplinas, habilidade e competências nas diferentes áreas); e (3) Atuação profissional atual (local, vínculo empregatício, tempo de trabalho, carga horária, interesse em outra área, escala de satisfação profissional, tempo e dificuldade de inserção no mercado de trabalho e filiação aos órgãos da classe). Outras três questões abertas permitiram opiniões e sugestões sobre a formação acadêmica e a perspectiva profissional.

Os resultados foram processados no programa Survey Monkey e analisados de forma descritiva, por meio de frequências absolutas e relativas ou e média, desvio padrão e valores mínimo e máximo, com auxílio do software Statistical Package for the Social Sciences (SPSS), versão 17.0 para Windows. ${ }^{20}$ 
As respostas abertas foram analisadas de forma quali-quantitativa, segundo a proposta de Toledo $^{8}$. Esse momento foi dividido em três etapas: (1) interpretação do conteúdo; (2) contabilização e frequência, com elaboração de categorias temáticas; e (3) posterior relação ao ano de entrada do egresso no curso.

Foram considerados nas análises tantos os egressos que afirmaram exercer a profissão de nutricionista, como os que alegaram atuar em outra área. Foram excluídos os questionários com menos de $50 \%$ das questões respondidas, os que tiveram duplicidade na autoria e daqueles que não eram formados.

O projeto da pesquisa foi aprovado pelo Comitê de Ética em Pesquisa (CEP) da UFS, em conformidade com a Resolução n⿳0 506/2016 sobre pesquisa envolvendo seres humanos, sob o Parecer $n^{\underline{0}} 1.807 .834$.

\section{Resultados e Discussão}

\section{Caracterização dos egressos}

Do total de formados $(n=225), 129$ responderam completamente ao questionário, correspondendo a 57,3\% de adesão à pesquisa. Predominou o sexo feminino (89,8\%), egressos na faixa etária entre 24 a 26 anos (47,3\%). A maioria dos formados (50,4\%) concluíram o curso em cinco anos, ultrapassando em um ano o tempo estimado (tabela 1). É importante evidenciar que, nos últimos anos, o país vem passando por crises políticas importantes, que ocasionaram várias manifestações, dentre as quais algumas greves nas universidades. Em decorrência, alguns períodos letivos foram irregulares, o que pode justificar a dilatação do prazo de conclusão do curso.

Cursar a graduação em maior tempo favorece o envolvimento em atividades de extensão. Durante o curso de Nutrição, 94,5\% dos egressos alegaram ter participado de alguma atividade extracurricular como monitoria, programa de iniciação científica ou projetos de extensão. Destes, a maioria $(45,8 \%)$ concluiu o curso em cinco anos e 66,4\% afirmaram ter conseguido emprego entre um a seis meses.

Em adição, os egressos avaliaram que o tempo de quatro anos para a graduação não favorece o aproveitamento de tais atividades com a profundidade e dedicação que gostariam, por terem muitas disciplinas por período. 
Tabela 1. Caracterização dos egressos do curso de Nutrição no Nordeste brasileiro, 2016 $(\mathrm{n}=129)$.

\begin{tabular}{|c|c|c|c|}
\hline \multicolumn{4}{|c|}{ Características dos egressos } \\
\hline & $\mathbf{X} \pm \mathbf{D P}$ & Mínimo & Máximo \\
\hline Idade (anos) & $25,6 \pm 2,1$ & 21 & 33 \\
\hline Duração do curso (anos) & $5,0 \pm 0,9$ & 4 & 8 \\
\hline Ano de entrada no curso & & $\mathrm{n}(\%)$ & \\
\hline 2007 & & $17(13,2)$ & \\
\hline 2008 & & $19(14,7)$ & \\
\hline 2009 & & $24(18,6)$ & \\
\hline 2010 & & $27(20,9)$ & \\
\hline 2011 & & $25(19,4)$ & \\
\hline 2012 & & $17(13,2)$ & \\
\hline \multicolumn{4}{|l|}{ Atuação profissional atual } \\
\hline Nutrição clínica & & $54(41,5)$ & \\
\hline Estudante & & $40(30,0)$ & \\
\hline Alimentação coletiva & & $19(14,6)$ & \\
\hline Docência & & $18(13,9)$ & \\
\hline Saúde Coletiva & & $13(10,0)$ & \\
\hline Nutrição esportiva & & $09(6,9)$ & \\
\hline Desempregado & & $08(6,2)$ & \\
\hline Abandonou a profissão & & $04(3,1)$ & \\
\hline Indústria de alimentos & & $02(1,5)$ & \\
\hline Marketing em alimentação e Nutrição & & $01(0,8)$ & \\
\hline
\end{tabular}

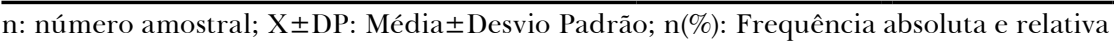


A partir de alguns estudos, ${ }^{6,7,21,22}$ foi possível perceber que as atividades de extensão são interessantes para todo aluno graduando, pois é esse momento em que se pode associar a teoria à prática e construir outros conhecimentos, ampliando e consolidando o aprendizado. Pinheiro et al. ${ }^{7}$ afirmam que essas atividades são necessárias e deveriam fazer parte do processo de ensino de forma em que a grade curricular fosse mais flexível para proporcionar a conexão entre a extensão e o ensino.

Observou-se que 41,5\% responderam que estão trabalhando atualmente em Nutrição Clínica, seguidos por 30,0\% que estão estudando (especialização / concurso), 6,2\% são desempregados e apenas 3,1\% abandonaram a profissão (tabela 1). A predominância da atuação na área Clínica foi corroborada pelo CFN em estudo ${ }^{23}$ realizado em 2006, com uma amostra de 2.492 nutricionistas de todo Brasil, evidenciando que 40,0\% dos entrevistados estavam alocados na área de Nutrição Clínica. Em contrapartida, o estudo de Sabba et al., ${ }^{24}$ em São Paulo, apontou que a área de Alimentação Coletiva foi a que mais abarcou os egressos participantes $(63,6 \%)$, seguida da Nutrição Clínica (29,5\%). Por se tratar de uma metrópole (São Paulo) com muitas empresas e indústrias, existem várias unidades de alimentação e nutrição que contratam profissionais da área.

Rocha \& Nozaki ${ }^{5}$ apontaram que 20,0\% dos egressos nutricionistas de um estado da Região Centro-Oeste estavam desempregados. Segundo Feix \& Poll, ${ }^{16}$ em um município da Região Sul, 6,5\% estavam desempregados, 8,4\% abandonaram a profissão e 1,8\% estavam estudando. Quanto ao presente estudo, os egressos de um curso da Região Nordeste desistiram menos da profissão e se inseriram mais em cursos de aperfeiçoamento; $72,2 \%$ ingressaram em algum programa de pós-graduação, sendo 47,6\% em especialização, 26,2\% em mestrado, 11,9\% residência e 6,4\% em doutorado acadêmico. Apenas 20,6\% ainda não ingressaram em uma pós-graduação, mas pretendem fazê-lo futuramente, e 7,1\% não pretendem ingressar e relataram já ter abandonado a profissão ou que têm o desejo de mudar de área.

Ressalta-se, ainda, que a maioria que relatou estar desempregada $(21,7 \%)$ fazia parte da última turma de formados (maio de 2016), fato que pode justificar o pouco tempo que tiveram para inserção no mercado de trabalho. Outra situação que tem sofrido modificação nos últimos anos é o aumento do número de profissionais de Nutrição em função das criações de novos cursos, aumentando a oferta dos profissionais no mercado de trabalho.

Aárea de maior preferência relatada foi a Nutrição Clínica (41,9\%), seguida da Saúde Coletiva (37,7\%), Docência (32,3\%), Nutrição Esportiva (19,2\%), Marketing na Área de Alimentação e Nutrição (9,2\%), Alimentação Coletiva (8,5\%) e Indústria de Alimentos (7,7\%). Foi constatado que 29,2\% dos participantes atuam na sua área de preferência, sendo que 68,8\% dos que atuam na Saúde Coletiva afirmaram ser a área de preferência, e dos que trabalham na Clínica, 38,9\% afirmaram ser essa sua área de preferência. Identificou-se lacuna na literatura relativa à avaliação da preferência pelas áreas da Nutrição entre os egressos, consistindo em importante questão a ser analisada, visando ao entendimento da satisfação profissional e da produtividade no trabalho. 
A maior parte dos participantes relatou ter como vínculo empregatício o setor privado (29,1\%), seguido do público $(25,2 \%)$ e autônomo $(22,8 \%)$, conforme a tabela 2 , divergindo do que foi encontrado por Dalla-Lana ${ }^{9}$ em Porto Alegre-RS, onde 43,0\% dos egressos nutricionistas eram funcionários públicos; 28,0\% autônomos e 17,0\% atuavam no serviço privado. A diferença na disponibilidade de concursos públicos entre as regiões Sul e Nordeste possivelmente justifica o contraponto.

Dos egressos absorvidos pelo mercado de trabalho, 46,5\% informaram que estão atualmente no emprego há, no máximo, um ano; 22,9\%, entre dois a três anos; e 10,3\% há mais de quatro anos. Sobre a carga horária semanal, 20,5\% trabalham 40 horas (tabela 2). Dos profissionais com quatro a seis anos no emprego, $18,2 \%$ estão vinculados ao serviço público e aqueles com tempo de até três anos, em sua maioria $(87,1 \%)$ são autônomos, demonstrando a estabilidade do primeiro.

Quanto à carga horária, os resultados foram corroborados por Rocha \& Nozaki ${ }^{5}$, onde 49,6\% dos egressos trabalham entre 30 a 40 horas semanais. Letro \& Jorge ${ }^{4}$ reforçaram que 30,0\% possuem uma carga horária superior a 40 horas semanal.

A maioria dos egressos $(71,7 \%)$ atua no próprio estado, sendo 50,4\% na capital. Resultados semelhantes foram encontrados em outros estudos: segundo Alves et al., ${ }^{15}$ tal se justifica pelo fato de a capital ser uma região que concentra as principais empresas e instituições, favorecendo maior oportunidade de emprego. O Conselho Federal de Nutricionistas (CFN) ${ }^{23}$ aponta que 66,7\% dos profissionais de nutrição exercem sua atividade profissional na sua cidade de origem. Esses dados estão de acordo com o presente estudo, uma vez que a maioria dos nutricionistas $(83,3 \%)$ dessa pesquisa está afiliada ao Conselho Regional de Nutricionista da quinta região (CRN-5), o qual faz parte dos estados de Sergipe e Bahia.

A inserção dos nutricionistas no mercado de trabalho pode ser considerada rápida, uma vez que $19,8 \%$ foram contratados de forma imediata, em decorrência do estágio ou por entrevista/ seleção de emprego, enquanto 46,0\% dos egressos foram empregados no período de um mês a seis meses. Esses resultados não estão muito distantes da realidade encontrada na Região Sudeste. Sabba et al. ${ }^{24}$, em São Paulo, evidenciaram que 69,0\% dos egressos informaram não ter passado por dificuldades para conseguir o primeiro emprego. Letro \& Jorge ${ }^{4}$ afirmaram que o mercado de trabalho está em busca de profissionais de nutrição recém-formados.

Mesmo com uma inserção rápida no mercado de trabalho, existem alguns obstáculos e dificuldades. Segundo os profissionais deste estudo, os principais são a baixa remuneração salarial $(46,0 \%)$, seguida de pouca oportunidade no mercado de trabalho (46\%). Também destacaram poucos concursos públicos e/ou vagas $(46,0 \%)$ e exigência de experiência profissional $(31,8 \%)$. Apenas 13,5\% relataram não ter encontrado dificuldades. Resultados são semelhantes ao estudo de Feix \& Poll ${ }^{16}$ conduzido na Região Sul. 
Tabela 2. Perfil profissional dos egressos do curso de Nutrição no Nordeste brasileiro, 2016 $(\mathrm{n}=127)$.

$\mathrm{n} \quad \%$

Vinculo empregatício

Privado 37 29,1

Público 32

25,2

Autônomo

29

22,8

Não se aplica

27

21,3

Outros

19

15,0

Tempo no emprego atual

Até 1 ano 59

46,5

2 a 3 anos

29

22,9

$>4$ anos

13

10,3

Não se aplica

26

20,5

Carga horária semanal do trabalho

$20 \mathrm{~h}$

15

11,8

$30 \mathrm{~h}$

17

13,4

$40 \mathrm{~h}$

26

20,5

$44 \mathrm{~h}$

13

10,2

Não se aplica

37

29,1

Outra carga horária

19

15,0

Localidade de trabalho

Aracaju

60

47,4

Outros

45

35,4

Não se aplica

22

17,3

n: número amostral; $\mathrm{n}(\%)$ : frequência absoluta e relativa. 


\section{Satisfação com o curso de formação e satisfação profissional}

De modo geral, o curso de Nutrição em estudo foi avaliado pelos egressos de forma satisfatória, obtendo quatro pontos como nota mais frequente $(58,7 \%)$ na escala de Likert de cinco pontos.

Do total de egressos que avaliaram a qualificação docente entre satisfeito e muito satisfeito (pontuações 4 e 5), 61,9\% atribuíram a nota 5. Em contrapartida, apresentaram uma satisfação mais baixa (40,5\%) com relação à estrutura física adequada, sendo a mesma frequência entre os agrupamentos de insatisfação e satisfação (tabela 3). Vale lembrar que o curso de Nutrição em questão foi o último a ser criado na Região Nordeste, inaugurado em 2007, com a estrutura física de laboratórios finalizada recentemente, em 2015, fato que pode explicar tal avaliação.

Quanto à satisfação profissional, os quesitos remuneração e carga horária foram os de maior insatisfação (60,2\% e 35,2\%, respectivamente), resultado semelhante ao de Rocha \& Nozaki ${ }^{5}$ em estudo conduzido com egressos insatisfeitos com a profissão pela baixa oferta de emprego e de salário justo. Para Rodrigues, ${ }^{25}$ a "realização profissional estaria agregada à realização financeira" (p. 22).

Infelizmente essas insatisfações são comuns na maioria das áreas de atuação da Nutrição. O piso salarial do nutricionista é considerado baixo atualmente, em comparação com outros profissionais da saúde, o que se torna motivo de desejo de mudança da área de Nutrição, segundo o estudo de Rodrigues et al. ${ }^{3}$ Alguns autores relatam que esses fatores são reflexos de desvalorização e falta de reconhecimento de classe. ${ }^{3,5,21}$

Para modificar essa situação, é preciso que os profissionais se mobilizem para que os representantes da classe trabalhem em função de melhorias nas condições de trabalho, como também para uma fiscalização efetiva. Muitas empresas tentam ludibriar esses profissionais com redução de carga horária, bem como com a oferta salarial desproporcional e, devido à falta de melhores oportunidades de emprego em algumas localidades, os profissionais aceitam tais condições.

Apesar de aproximadamente 47,0\% dos egressos se declarar como satisfeitos e muito satisfeitos quanto à realização profissional, chama atenção que 22,0\% se colocam como indiferentes a essa avaliação.

As demais variáveis sobre satisfação profissional foram mais pontuadas na escala com satisfação (4 pontos), mostrando que, para esse público, a área da Nutrição favorece a criatividade e a autonomia, bem como oportuniza novas aprendizagens e desenvolvimento profissional, além de ser considerada uma área de relevância social. 
Tabela 3. Avaliação dos fatores relativos à formação e satisfação profissional dos egressos de um curso de Nutrição no Nordeste brasileiro, 2016.

\begin{tabular}{|c|c|c|c|}
\hline Formação profissional (n=126) & $\begin{array}{c}\text { Insatisfeitos } \\
(\%)\end{array}$ & $\begin{array}{l}\text { Indiferentes } \\
\qquad(\%)\end{array}$ & $\begin{array}{c}\text { Satisfeitos } \\
(\%)\end{array}$ \\
\hline Adequação do currículo / disciplinas & 15,9 & 7,9 & 76,2 \\
\hline $\begin{array}{l}\text { Ambiente intelectualmente } \\
\text { desafiador / estimulante }\end{array}$ & 7,1 & 17,5 & 75,4 \\
\hline $\begin{array}{l}\text { Estrutura física adequada } \\
\text { (como laboratórios e salas) }\end{array}$ & 40,5 & 19,0 & 40,5 \\
\hline Oportunidade de aprendizado ativo & 10,3 & 12,7 & 77,0 \\
\hline Capacidade de comunicação oral e escrita & 6,3 & 8,7 & 84,9 \\
\hline Ética profissional e responsabilidade social & 3,2 & 6,3 & 90,5 \\
\hline Qualificação dos docentes & 2,4 & 1,6 & 96,0 \\
\hline \multicolumn{4}{|l|}{ Satisfação profissional $(n=128)^{1}$} \\
\hline Remuneração & 60,2 & 9,4 & 21,9 \\
\hline Prestígio & 30,5 & 24,2 & 37,5 \\
\hline Relações de trabalho & 9,4 & 18,0 & 60,9 \\
\hline Oportunidade de crescimento & 27,3 & 19,5 & 45,3 \\
\hline Autonomia & 15,6 & 19,5 & 58,6 \\
\hline Realização profissional & 26,6 & 21,9 & 46,9 \\
\hline Ambiente/ferramentas de trabalho & 24,2 & 16,4 & 49,2 \\
\hline Relevância social do trabalho & 11,7 & 14,1 & 63,3 \\
\hline Carga horária de trabalho & 35,2 & 21,1 & 32,0 \\
\hline $\begin{array}{l}\text { Oportunidade de desenvolvimento } \\
\text { profissional }\end{array}$ & 23,4 & 21,9 & 47,7 \\
\hline Oportunidade de exercer a criatividade & 10,9 & 15,6 & 65,6 \\
\hline Oportunidade de novas aprendizagens & 11,7 & 9,4 & 69,5 \\
\hline
\end{tabular}

n: número amostral; (\%) frequência relativa.

${ }^{1}$ As respostas apresentadas na tabela não contemplam os profissionais que não estão trabalhando (Opção 6 - "não se aplica"). 


\section{Avaliação dos egressos em relação ao curso e perspectivas profissionais}

$\mathrm{Na}$ análise das questões abertas, que abordavam propostas e aprimoramento do curso e perspectivas profissionais, foi permitido aprofundar as opiniões dos egressos.

Na percepção de $86,4 \%$ dos participantes, os aspectos que podem ser melhorados nesse curso de graduação em Nutrição são: mais aulas práticas $(45,4 \%)$, aprimoramento de disciplinas (18,5\%), estrutura física/laboratórios $(15,7 \%)$, maior duração do curso $(12,0 \%)$ e melhorias da grade curricular $(13,9 \%)$.

A necessidade de aulas mais práticas no curso pode ser evidenciada pelo relato de um egresso:

Os estudantes deveriam ser submetidos a mais aulas práticas. Ter o contato com as áreas bases em conjunto com as teorias, como ocorre em Odontologia ou Medicina, por exemplo. [...] a realidade com o público é muito diferente das aulas práticas baseadas em pacientes fictícios ou encontros esporádicos. Deixar que os alunos vivenciem a realidade apenas nos estágios obrigatórios proporciona uma insegurança no momento da inserção no mercado de trabalho. (E18).

Conforme já mencionado, as aulas práticas são importantes para o melhor aprendizado e aplicabilidade na vida profissional. Algumas universidades trabalham com o método Problem-Based Learning (PBL ou Aprendizagem Baseada em Problemas), onde são desenvolvidas situações reais/ simuladas em que o aluno pratica o conteúdo estudado recentemente, desenvolvendo habilidade e competências para sua vida profissional. No entanto, para transitar do método convencional de ensino para o PBL, existem algumas barreiras burocráticas e institucionais, sendo necessárias várias adaptações, incluindo a abertura de campos de prática. Mesmo assim, é possível encontrar um equilíbrio, com a utilização de mais práticas e, assim, promover mudanças no ensino. ${ }^{6,21,22}$

De modo geral, a maioria dos docentes se prende ao ensino tradicional e transmite os conteúdos de forma programática, nem sempre utilizando ferramentas tecnológicas ou discussões abertas sobre assuntos polêmicos do cotidiano que poderiam colaborar na transmissão da informação. O curso de Nutrição deve ser planejado de forma a permitir que o profissional atue na sociedade, percebendo seu papel social, fundamentado nas relações interpessoais e do conhecimento, ${ }^{6,21,26,27}$ o que pressupõe realizar debates sobre temas de cunho social e antropológico, para uma atuação mais efetiva.

Para formar um profissional apto a atuar de modo interdisciplinar em equipes multiprofissionais, é preciso renovar a forma de ensinar-aprender, que é o único caminho que possibilitaria novos projetos pedagógicos, novas condições e percepções. De acordo com as Diretrizes Curriculares Nacionais, o nutricionista é o profissional da saúde com formação generalista, humanista e crítica, guiado por princípios éticos e com reflexão sobre a realidade econômica, política, social e cultural das comunidades. 
Deste modo, a formação em Nutrição tem como objetivo possibilitar o exercício das habilidades e competências gerais, em relação à atenção a saúde, tomada de decisões, comunicação, administração, gerenciamento e educação permanente. ${ }^{28,29}$ No entanto, superar o tradicional modelo de ensinoaprendizagem no ensino superior ainda é um desafio, no sentido de torná-lo mais horizontalizado, menos coercitivo, sobretudo do que diz respeito às avaliações, e mais participativo.

Alguns egressos se manifestaram a favor da duração maior do curso para cinco anos $(12,0 \%)$, justificando a melhor diluição das disciplinas e melhor aproveitamento das atividades extracurriculares e, consequentemente, melhor aproveitamento do curso, segundo os participantes.

As dificuldades estruturais mencionadas por 15,7\% dos egressos foram relativas à carência de laboratórios adequados. A esse respeito, cabe a reflexão de Luz et al. ${ }^{21}$ quanto ao aumento do número de vagas nas universidades públicas por parte do governo, aliado a uma redução dos recursos financeiros, que tem produzido uma formação deficiente em estrutura e materiais aos docentes. Sabe-se que para ter uma formação com qualificação profissional capaz de desenvolver habilidades para realizar suas atribuições com qualidade, é necessário que as universidades ofereçam materiais, equipamentos e estrutura física apropriados.

Quanto às perspectivas profissionais, a maioria dos respondentes expressou interesse em ingressar na docência e se especializar, alcançando valorização e reconhecimento profissionais, com melhor remuneração, mais oportunidade de emprego e adequação de carga horária de trabalho; e ainda, foi relatado proporcionar melhor qualidade de vida ao paciente.

De modo geral, é notável que os egressos deste estudo mostraram perspectivas positivas em relação à profissão. É importante salientar que o fato de boa parte desejar continuar estudando propiciará atuação mais qualificada, melhorando a atuação e a visibilidade da profissão.

A maior limitação deste estudo foi o período de coleta de dados, realizada no final do ano, em meio a férias e festividades. Outro motivo que pode explicar a adesão ao estudo é o número de endereços eletrônicos desatualizados, fator que foi controlado pela divulgação nas redes sociais.

\section{Conclusão}

Constatou-se que o curso, de modo geral, foi avaliado positivamente pelos egressos, mas que existem pontos a serem trabalhados para melhorias, tais como mais aulas práticas e aprimoramento de disciplinas. Para isso, é preciso que os gestores do curso e da instituição busquem as adequações necessárias ao profissional no campo de trabalho para nortear ações futuras. Fomentar o lado crítico constitui uma responsabilidade mútua entre discentes e docentes, para um ensino com maior potencial de formar profissionais preparados para o mercado de trabalho, capazes de ser agentes de transformação social. 
Foi possível identificar diferenças entre os resultados encontrados neste estudo e aqueles realizados na Região Sudeste, quanto às dificuldades para inserção no mercado de trabalho. Por outro lado, observou-se que a insatisfação profissional, atrelada à baixa remuneração e à elevada carga de trabalho, foram bastante semelhantes aos resultados encontrados em outras regióes e estados. Para superar tais desafios, são necessárias medidas mais abrangentes no que diz respeito a reformas curriculares e modificaçôes do tradicional modelo de ensino-aprendizagem.

Destaca-se a importância de uma análise contínua desses profissionais, visto que é uma profissão que vem crescendo e ganhando espaço no mercado de trabalho. As propostas e sugestões relativas à melhoria do curso foram encaminhadas à equipe responsável pela reformulação da formação acadêmica, cumprindo o verdadeiro objetivo da pesquisa científica.

\section{Colaboradores}

Souza JCN participou da concepção, delineamento, coleta e análise dos dados e redação do artigo; Fagundes A participou da concepção, delineamento, análise dos dados e revisão do artigo; da Sila DG participou da concepção, delineamento, análise crítica da pesquisa e revisão do artigo; Barbosa KBF participou da análise crítica da pesquisa e revisão do artigo.

Conflito de interesses: Os autores declaram não haver conflito de interesse.

\section{Referências}

1. Brasil. Conselho Federal de Nutricionistas. A história do Nutricionista no Brasil [Internet]. [acesso em: 14 jul. 2016]. Disponível em: http://www.cfn.org.br/eficiente/repositorio/Comunicacao/ Material_institucional/160.pdf

2. Cristofolli C, Bonato L, Ravazzani EDA. Análise histórica da profissão de nutricionista. Cadernos da Escola de Saúde. Curitiba 2011; 2(6):1-7.

3. Rodrigues KM, Peres F, Waissmann W. Condições de trabalho e perfil profissional dos nutricionistas egressos da Universidade Federal de Ouro Preto, Minas Gerais, entre 1994 e 2001. Ciênc Saúde Coletiva. 2007; 12(4):1021-1031.

4. Letro LCMAOL, Jorge MN. Inserção profissional dos nutricionistas egressos do Centro Universitário do Leste de Minas Gerais, Unileste/MG. NutrirGerais, Ipatinga-MG. 2010; 4(7):668-680.

5. Rocha PMN, Nozaki VT. Perfil profissional dos nutricionistas egressos da UNIGRAN. Interbio. 2012; 6(2):70-80.

6. Calças IRR, Gianlupi K, Missio L, Alvarenga MRM. A formação do nutricionista sob a perspectiva do currículo em saúde. Interfaces da Educ. Paranaíba. 2016; 7(19):361-375. 
7. Pinheiro ARO, Recine E, Teixeira BA, Fagundes AA, Sousa JSde, Monteiro RA, et al. Percepção de professores e estudantes em relação ao perfil de formação do nutricionista em saúde pública. Rev Nutr. 2012; 25:631-643.

8. Toledo ADA. Saúde, formação e trabalho: perspectiva do nutricionista ao longo do sete décadas [dissertação]. [São Paulo]: Universidade de São Paulo; 2014.

9. Dalla-Lana M. Estudo sobre a situação profissional dos egressos do curso de nutrição da Universidade Federal do Rio Grande do Sul [especialização]. [Porto Alegre]: Universidade Federal do Rio Grande do Sul; 2010.

10. Recine E, Gomes RCF, Fagundes AA, Pinheiro ARO, Teixeira BA, Sousa JS, et al. A formação em saúde pública nos cursos de graduação de nutrição no Brasil. Rev Nutr. 2012; 25(1):21-33.

11. Associação Brasileira de Nutrição. Nutrição em números: uma profissão que não para de crescer [Internet]. [acesso em: 30 jul. 2016]. Disponível em: http://www.asbran.org.br/numeros.php

12. Brasil. Conselho Federal de Nutricionistas. Quadro Estatístico 1 ${ }^{\circ}$ Trimestre de 2016 [acesso em: 14 jul. 2016]. Disponível em: http://www.cfn.org.br/index.php/estatistica/

13. Franco AC, Boog MCF. Relação teoria-prática no ensino de educação nutricional. Rev Nutr. Pontifícia Universidade Católica de Campinas, 2007; 20(6):643-655.

14. Universidade Federal de Sergipe. Resolução no 168/2009/CONEPE/UFS. Aprova alterações no Projeto Pedagógico do Curso de Graduação em Nutrição Modalidade Bacharelado - Curso 235 - e dá outras providências. Sala das Sessões, 18 de dezembro de 2009. Atos da Reitoria. 15 jul. 2010

15. Alves E, Rossi CE, Vasconcelos FAG. Nutricionistas egressos da Universidade Federal de Santa Catarina: áreas de atuação, distribuição geográfica, índices de pós-graduação e de filiação aos órgãos de classe. Rev Nutr. 2003; 16(3):295-304.

16. Feix M, Poll FA. Perfil profissional de nutricionistas egressos da Universidade de Santa Cruz do Sul. Cinergis. 2015; 16(4):242-248.

17. Universidade Federal de Sergipe. UFS em números [Internet]. [acesso em: 12 dez. 2016]. Disponível em: http://oficiais.ufs.br/pagina/8626

18. Timoteo ME. Acompanhamento de egressos e avaliação de cursos de pós-graduação stricto sensu: uma proposta para mestrados profissionais [mestrado]. [Rio de Janeiro]: Escola Nacional de Saúde Pública Sergio Arouca; 2011.

19. Gil AC. Métodos e técnicas de pesquisa social. 6 ed. São Paulo: Atlas; 2008.

20. Software Statistical Package for the Social Sciences. versão 17.0 para Windows. Chicago: SPSS; 2008.

21. Luz MMA, Romero ABR, Brito AKS, Batista LPR, Nogueira LT, Santos MM, et al. A formação do profissional nutricionista na percepção do docente. Interface. 2015; 19(54):589-601.

22. Duarte ALA, Monaco CF, Manso MEG. A Aprendizagem baseada em problemas no ensino das ciências básicas: experiência no segundo semestre do curso de Medicina de um Centro Universitário. Mundo da Saúde. 2013; 37(1):89-96.

23. Brasil. Conselho Federal de Nutricionistas. Inserção profissional dos nutricionistas no Brasil 2006 [acesso em: 28 jul. 2016]. Disponível em: http://www.cfn.org.br/novosite/pdf/pesquisa.pdf 
24. Sabba LJ, Okida Y, Oliveira CRA, Coutinho RMC, Coelho HDS. Perfil de egressos do curso de nutrição da Universidade Paulista de um campus em São Paulo. J Health Sci Inst. 2014; 32(4):424-427.

25. Rodrigues KM.Condições de trabalho do nutricionista egresso da Universidade Federal de Ouro Preto/ MG: subsídios para a construção de indicadores qualitativos de satisfação profissional [mestrado]. Rio de Janeiro: Fundação Oswaldo Cruz, Escola Nacional de Saúde Pública; 2004.

26. Soares NT, Aguiar ACde. Diretrizes curriculares nacionais para os cursos de nutrição: avanços, lacunas, ambiguidades e perspectivas. Rev Nutr. 2010; 23(5):895-905.

27. Meira MDD, Kurcgant P. Avaliação de curso de graduação segundo egressos. Rev Esc Enferm USP. 2009; 43(2):481-485.

28. Recine E, Mortoza A. Consenso sobre habilidades e competências do nutricionista no âmbito da saúde coletiva. Brasília: Observatório de Políticas de Segurança e Nutrição; 2013.

29. Recine E, Sugai A, Monteiro RA, Fagundes A, Rizzolo A. Saúde coletiva nos cursos de Nutrição: análise de projetos político-pedagógicos e planos de ensino. Rev Nutr. 2014; 27(6):747-760.

Recebido: 03 de maio, 2017

Revisado: 26 de junho, 2017

Reapresentado: 29 de janeiro, 2018

Aceito: 01 de fevereiro, 2018 